\title{
Serum Vitamin D Levels in Indian Patients with Multiple Sclerosis
}

\author{
Radhakrishnan Suresh Kumar • Sajid Syed • \\ Anandakuttan Anand Kumar • K. N. Subha Kumari • \\ K. Sajitha
}

Received: 3 August 2012/Accepted: 23 September 2012/Published online: 11 October 2012

(C) Association of Clinical Biochemists of India 2012

\begin{abstract}
Low serum vitamin D level has an increased association with risk of multiple sclerosis (MS).There has been no published data on the levels of this vitamin in Indian population with MS. Hence we decided to undertake this study to document if there is evidence of vitamin D deficiency in patients with MS in our population. 26 patients with diagnosis of MS by modified Mc Donald's criteria were enrolled in this study. Serum vitamin D $(1,25$ hydroxy) levels were measured by electro-chemiluminescence in our biochemistry lab. An age-matched control group of 202 patients who did not have a diagnosis of MS were included. In our study group $76.9 \%$ had vitamin D level less than $20 \mathrm{ng} / \mathrm{ml}$ compared to $65.5 \%$ of control group ( $p$ value of 0.019). Our study revealed a trend towards low vitamin D values in Indian MS patients.
\end{abstract}

Keywords Vitamin D · Multiple sclerosis $\cdot$ Sunlight

\section{Introduction}

Multiple sclerosis (MS) is predominantly a disease of the temperate climate [1]. However with better investigation tools like MRI Brain we are increasingly diagnosing MS in

R. Suresh Kumar · S. Syed · A. Anand Kumar

Department of Neurology, Amrita Institute of Medical Sciences,

Kochi, India

R. Suresh Kumar $(\bowtie)$

G389, Panampilly Nagar, Kochi 682036, India

e-mail: rsureshkumar@aims.amrita.edu

K. N. Subha Kumari · K. Sajitha

Department of Biochemistry, Amrita Institute of Medical

Sciences, Kochi, India the Indian subcontinent. Given the population of our country even with a low prevalence, the number of patients suffering from the disease may be high. We know that genetic, environmental and infective factors play an important role in the aetiology of the disease. However vitamin $\mathrm{D}$ deficiency is now increasingly being investigated as a triggering factor. The source of vitamin D in human beings is dependent mainly on exposure to sunlight. There is a decline in ultra violet ray exposure as we move to higher latitudes. During the winter at high latitudes, ultraviolet sunrays is too low to produce adequate amounts of vitamin D3. Hence at latitudes higher than $42^{\circ}$ vitamin $\mathrm{D}$ deficiency is common especially among those with poor dietary intake $[2,3]$. Studies on vitamin D and MS have found that individuals with MS tend to have insufficient vitamin D levels $[4,5]$ and that periods of low vitamin D levels precede the occurrence of high lesional activity and vice versa as detected by MRI $[6,7]$. The prospect of a potential tool to prevent MS is tempting, yet challenging. Hence supplementation has not only been proposed to prevent relapses, but also to attenuate disease activity of MS [8, 9]. Vitamin D has been shown to have many immuno-modulatory effects in preventing relapses $[10,11]$. This sparked the interest in a poor vitamin D exposure as a risk factor for developing MS. No published data is available on vitamin D levels in Indian population with MS and a positive study can definitely have therapeutic effects in a country like ours with a low socio economic status where interferons are beyond the reach of most patients.

\section{Materials and Methods}

In the present study we aimed at measuring the serum vitamin D level in patients with confirmed diagnosis of MS 
attending the MS clinic in Amrita Institute of Medical Sciences and Research Centre (AIMS), Kochi, Kerala. These patients fulfilled the Mc Donald Criteria 2005. The study population was compared with controls that were aged matched patients and were not on any vitamin D supplementation or having any chronic debilitating illness leading to secondary vitamin $\mathrm{D}$ deficiency.

\section{Method of Vitamin D Estimation}

The estimation of 1,25 hydroxy vitamin D was done in our biochemistry lab by an Electro-chemical luminescent method (Elecsys 2010 as instrument and with Roche reagent kit). The normal range estimated is $20-30 \mathrm{ng} / \mathrm{ml}$.

\section{Statistical Method}

Statistical significance of the difference in the mean values was tested using Student's $t$ test.

Due to non-normal distribution of the values of both the variables, analysis was done on their log values.

\section{Results}

Numbers of Cases were 26, of which 23 were females with age matched 202 controls. Mean age of cases were 32.6 years and controls were 37.5 years. Of the cases 23 were relapsing remitting type, two secondary progressive.

Mean vitamin D value for cases was 14.84 and for controls were 18.55 . The statistical significance between the means was assessed using students $t$ test and the $p$ value was 0.019 . Controls of 202 patients has been included in the study for achieving statistical significance (Table 1; Fig. 1).

\section{Discussion}

The prevalence of MS is almost close to zero near the equator and is markedly increased as we go up towards the temperate regions. One hypothesis is that sunlight exposure and the resulting increase in vitamin D may exert a protective effect for people in the tropics [12-14]. Some exceptions for this latitude gradients are districts in Switzerland at altitudes $>2,000 \mathrm{~m}$ above sea level $[15,16]$, Greenland and coastal regions of Norway were the

Table 1 Vitamin D study group

\begin{tabular}{lllll}
\hline Variables & Number & Mean & SD & $p$ value \\
\hline Cases & 26 & 14.84 & 6.69 & - \\
Controls & 202 & 18.55 & 7.74 & 0.019 \\
\hline
\end{tabular}

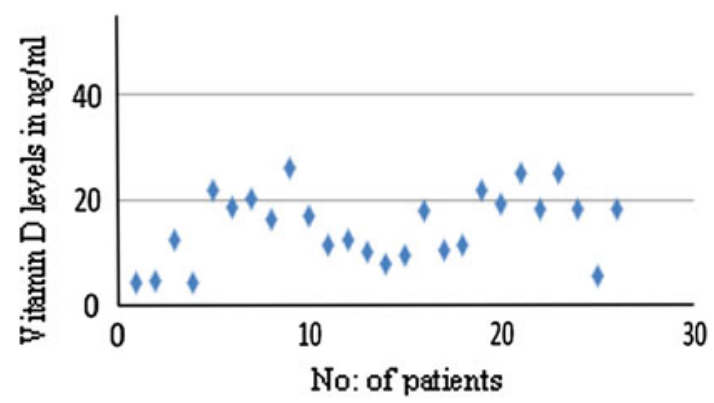

Fig. 1 Serum vitamin D levels in $\mathrm{ng} / \mathrm{ml}$ in the $\mathrm{Y}$ axis and the study population in the $\mathrm{x}$ axis

prevalence of MS were lower [17, 18], Results are consistent with the hypothesis that inadequate vitamin D status is an important pathogenic factor in MS. Annual UV B radiation is more intensive in Swiss districts at higher altitude than those at sea level. Hence higher vitamin D levels at these altitudes are associated with lower prevalence of MS. In Greenland and in coastal Norway there is traditionally high consumption of vitamin D rich fatty fish. Hence the coastal regions have lower prevalence of the disease compared to inland.

However the clearest evidence for risk of MS in individuals with low vitamin D levels comes from the largest nested case control studies done in seven million American soldiers [19] their blood samples were stored in the department of defence serum repository in 1992. Multiple sclerosis cases were identified through Army and Navy physical disability databases from 1992 to 2004 and diagnoses were confirmed by medical record review. The vitamin D levels of soldiers with diagnosis of MS were compared with age, sex and ethnic matched controls. The conclusion of the study was that those soldiers with high vitamin D levels at the time of recruitment had lower incidence of MS.

The most widely used score to quantify disability due to MS is the expanded disability status scale (EDSS). EDSS score has been reported to correlate negatively with serum 25(OH)D level [20]. EDSS-score also correlated negatively with recent sun exposure [21].

Relapse activity has also been related to vitamin $\mathrm{D}$ status. During relapse, lower serum 25(OH) D levels have been reported in several MS populations, when compared to in remission [22, 23]. Also more gadolinium enhancing lesions on T1 MRI have been reported in Germany in spring and early summer, and less in autumn [24].

Hence vitamin D also produces immunomodulatory effects on the disease and helps either in preventing it or decreases its effects when it occurs [25, 26].

There are also therapeutic benefits to treatment with vitamin D supplementations and evidences show that there is reduction in the number of relapses when patients are 
treated with high doses of vitamin D. Burton et al. performed a small phase I/II study which compared two groups of MS patients supplemented with either high (up to $40,000 \mathrm{IU} /$ day) or low doses (4,000 IU/day) of vitamin D3 for 52 weeks. They reported a smaller proportion of patients with progression on the EDSS-scale in the higher supplemented group when compared to low dose vitamin D group (2/25 vs. 9/24, respectively) [27].

Our study population were from the state of Kerala in south India who inherently have very low chance of developing MS due to proximity to the equator and also because they predominantly eat sufficient amount of vitamin D rich fatty fishes as a part of their regular diet. However there are also some factors in this population that can favour the development of MS. One is the colour of their skin and the second being less of sunlight exposure due to more people taking up white collar jobs. It has been shown that dark skinned people requires longer duration of exposure to sun to produce the same amount of vitamin D levels than in fair skinned individuals.

In this study we found that the mean value of vitamin in the case study group $(14.84 \mathrm{ng} / \mathrm{ml})$ and controls $(18.55$ $\mathrm{ng} / \mathrm{ml})$ were below the normal range $(20-30 \mathrm{ng} / \mathrm{ml})$. The mean value in cases showed a statistically significant ( $p$ value 0.05 ) decrease in vitamin D levels when compared to age matched controls even though the controls also had lower mean value than normal. The dark skinned nature and decreased sun exposures might be the reason for the reduced levels of vitamin $\mathrm{D}$ in both study groups.

\section{Conclusion}

Serum vitamin D levels were low in the study population. To our knowledge this is the first study looking at serum vitamin D levels in patients with MS in the Indian population. Though our study was done on a small number of patients MS itself is a rare disease with low prevalence rate compared to many other neurological disorders. Our study has revealed a trend towards low vitamin $\mathrm{D}$ values in Indian MS patients. We need more studies in other parts of the country to confirm this trend and to look at vitamin D levels during both relapses as well as remission and with duration of sunlight exposure.

\section{References}

1. Kurtzke JF. Geography in multiple sclerosis. J Neurol. 1977;215:1-26.

2. Webb AR, Kline L, Holick MF. Influence of season and latitude on the cutaneous synthesis of vitamin D3: exposure to winter sunlight in Boston and Edmonton will not promote vitamin D3 synthesis in human skin. J Clin Endocrinol Metab. 1988;67:373-8.

3. Ladizesky M, Lu Z, Oliveri B, San RN, Diaz S, Holick MF, Ladizesky M, Lu Z, Oliveri B, San RN, Diaz S, Holick MF, et al. Solar ultraviolet $\mathrm{B}$ radiation an photo production of vitamin D3 in central and southern areas of Argentina. J Bone Miner Res. 1995;10:545-9.

4. Cosman F, Nieves J, Herbert J, Shen V, Lindsay R. High-dose glucocorticoids in multiple sclerosis patients exert direct effects on the kidney and skeleton. J Bone Miner Res. 1994;9:1097-105.

5. Nieves J, Cosman F, Herbert J, Shen V, Lindsay R. High prevalence of vitamin D deficiency and reduced bone mass in multiple sclerosis. Neurology. 1994;44:1687-92.

6. Auer DP, Schumann EM, Kumpfel T, Gossl C, Trenkwalder C. Seasonal fluctuations of gadolinium-enhancing magnetic resonance imaging lesion in multiple sclerosis. Ann Neurol. 2000;47:276-7.

7. Embry AF, Snowdon LR, Vieth R. Vitamin D and seasonal fluctuation of gadolinium-enhancing magnetic resonance imaging lesions in multiple sclerosis. Ann Neurol. 2000;48:271-2.

8. Simpson S Jr, Taylor B, Blizzard L. Higher 25-hydroxyl vitamin $\mathrm{D}$ is associated with lower relapse risk in multiple sclerosis. Ann Neurol. 2010;68(2):193-203.

9. Mowry EM, Krupp LB, Milazzo M, Chabas D, Strober JB, Belman AL, et al. Vitamin D status is associated with relapse rate in pediatric-onset multiple sclerosis. Ann Neurol. 2010;67(5): 618-24.

10. Correale J, Ysrraelit MC, Gaitán MI. Immunomodulatory effects of Vitamin D in multiple sclerosis. Brain. 2009;132(5):1146-60.

11. Smolders J. Vitamin D as an immunomodulator in Multiple sclerosis. J Neuroimmunol. 2008;194:7-17.

12. Acheson ED, Bachrach CA, Wright FM. Some comments on the relationship of the distribution of multiple sclerosis to latitude, solar radiation and other variables. Acta Psychiatr Scand. 1960;35(suppl 147):132-47.

13. Sutherland JM, Tyrer JH, Eadie MJ. The prevalence of multiple sclerosis in Australia. Brain. 1962;85:146-64.

14. Leibowitz U, Sharon D, Alter M. Geographical considerations in multiple sclerosis. Brain. 1967;90:871-86.

15. Kurtzke JF. On the fine structure of the distribution of multiple sclerosis. Acta Neurol Scand. 1967;43:257-82.

16. Geiger R. The climate near the ground. Cambridge: Harvard University Press; 1965. p. 442-6.

17. Presthus J. Report on the multiple sclerosis investigations in West Norway. Acta Psychiatr Neurol Scand. 1960;35(Suppl 147): $88-92$.

18. Westlund K. Distribution and mortality time trend of multiple sclerosis and some other diseases of Norway. Acta Neurol Scand. 1970;46:455-83.

19. Munger KL, Levin LI, Hollis BW, Howard NS, Ascherio A. Serum 25-Hydroxyvitamin D levels and risk of multiple sclerosis. JAMA. 2006;296(23):2832-8.

20. Smolders J, Menheere P, Kessels A, Damoiseaux J, Hupperts R. Association of vitamin D metabolite levels with relapse rate and disability in multiple sclerosis. Mult Scler. 2008;14(9):1220-4.

21. Van der Mei IA, Ponsonby AL, Dwyer T, Blizzard L, Taylor BV, Kilpatrick T, et al. Vitamin D levels in people with multiple sclerosis and community controls in Tasmania, Australia. J Neurol. 2007;254(5):581-90.

22. Soilu-Hänninen M, Airas L, Mononen I, Heikkilä A, Viljanen M, Hänninen A. 25-hydroxyvitamin D levels in serum at the onset of multiple sclerosis. Mult Scler. 2005;11(3):266-71.

23. Soilu-Hänninen M, Laaksonen M, Laitinen I, Erälinna JP, Lilius EM, Mononen I. A longitudinal study of serum 25-hydroxyvitamin D and intact parathyroid hormone levels indicate the importance of vitamin $\mathrm{D}$ and calcium homeostasis regulation in 
multiple sclerosis. J Neurol Neurosurg Psychiatr. 2008;79(2): $152-7$.

24. Auer DP, Schumann EM, Kümpfel T, Gössl C, Trenkwalder C. Seasonal fluctuations of gadolinium-enhancin magnetic resonance imaging lesions in multiple sclerosis. Ann Neurol. 2000;47(2):276-7.

25. Smolders J, Mariëlle T, Evelyn P, Paul M, Jan WCT, Jan D, et al. Vitamin D status is positively correlated with regulatory $\mathrm{T}$ cell function in patients with multiple sclerosis. PLoS ONE. 2009;4(8):e6635.
26. Holmøy T, Moen SM, Gundersen TA, Holick MF, Fainardi E, Castellazzi M, et al. 25-hydroxyvitamin D in cerebrospinal fluid during relapse and remission of multiple sclerosis. Mult Scler. 2009;15(11):1280-5.

27. Burton JM, Kimball S, Vieth R, Bar-Or A, Dosch H-M, Thibault $\mathrm{L}$, et al. A Phase I/II dose-escalation trial of oral vitamin D3 with calcium supplementation in patients with multiple sclerosis. Mult Scler. 2008;14(Suppl 1):S34. 